\title{
Simulating Daylighting and Energy Demand for Lighting of Buildings with Different Models and Programs: Analysis of Influencing Factors and Comparison of Results
}

\author{
Anna Pellegrino ${ }^{1}$, Valerio R.M. Lo Verso ${ }^{1}$, Argun Paragamyan ${ }^{1}$ \\ ${ }^{1}$ Dept. of Energy 'Galileo Ferraris', Politecnico di Torino, TEBE Research Group, Turin, Italy
}

\begin{abstract}
The calculation of the energy demand for lighting, including the daylight provision, is a key aspect of the process to assess the energy performance of a building.

This paper compares a simplified model, from the European Standard EN 15193:2017, and a dynamic simulation tool, DIVA-for-Rhino. Both tools are designed to calculate climate-based daylighting conditions and the consequent energy demand for lighting. The two approaches were applied to a set of case studies. An analysis of correspondences and discrepancies of the methods and of the results is presented.
\end{abstract}

\section{Introduction}

Lighting of indoor and outdoor spaces is one of the key factors for the total consumption of primary energy at a large scale and the subsequent $\mathrm{CO}_{2}$ footprint. In the building sector, strategies to reduce the consumption for lighting are concerned with energy efficiency of products and systems and with energy saving oriented behaviour of users. At a building scale, the performance of lighting systems needs to be evaluated accounting for a number of interconnected factors: component efficiency, presence of control systems for lights and shades, user behaviour and daylighting in indoor spaces (Dubois et al., 2011).

The standard EN 15193-1 (2017) belongs to a set of standards developed to support the implementation of the Energy Performance of Buildings Directives. In the standard, a metric (Lighting Energy Numeric Indicator LENI) was introduced to quantify the energy demand for lighting for a building. An analytical calculation method was also supplied, whose basic principles are described in ISO 10916 (2014). This includes all the main influencing factors: power of lighting systems, daylight contribution in a space, type of lighting control and building usage. The "core" of the calculation method is the estimation of the daylight contribution: this is done accounting for the architectural features of the considered building, including windows and moveable shading systems, as well as for the specific climate of the considered site.

Consequently, building practitioners are supplied with a detailed analytical method, which accounts for climate conditions, orientations and movable shadings, occupancy of a space and type of lighting control systems, to calculate the daylight availability and energy demand for lighting without running any simulations.
A high number of variables were implemented in the method, but they are considered in a simplified way compared to an advanced simulation tool. The climate conditions are considered through discrete ranges of latitudes and of luminous exposure $L E$, which is the ratio of direct to global external illuminance - $\mathrm{H}_{\text {dir }} / \mathrm{H}_{\text {glob }}$ (both calculated annually by summing up hourly contributions from 8:00 to 17:00). Discrete ranges are also used for the daylight penetration and for illuminance values, and a limited number of shading systems are available. The method is tabular, while the most advanced simulations tools allow, in principle, any value of above variables (climate, geometries, shading systems, etc.) to be implemented to determine daylighting and the energy demand for lighting for a space.

Within this frame, this paper presents a study on the comparison of these two approaches to daylight and energy demand for lighting determination, through the analytical method of the standard and through DIVA-forRhino simulations. For the purpose, an office room was used, located in different sites and with different orientations and windows (with or without mobile shades), and different types of lighting controls. Both the daylighting and the energy demand for lighting were calculated through the two approaches (analytical vs. DIVA). The goal was to provide information useful to a building design team on consistencies and discrepancies of the two approaches, which rely on different algorithms and assumptions in reproducing the complexity of the physical phenomena of lighting in buildings.

\section{Theory: approaches to calculate daylighting and energy demand for lighting}

\section{Approach of standard EN 15193-1:2017}

The analytical method is based on the following formulae:

$$
\begin{array}{ll}
\text { LENI }=\frac{\mathrm{W}}{\mathrm{A}}=\frac{\mathrm{W}_{\mathrm{L}, \mathrm{t}}+\mathrm{W}_{\mathrm{P}, \mathrm{t}}}{\mathrm{A}} & {\left[\frac{\mathrm{kWh}}{\mathrm{m}^{2} \text { year }}\right]} \\
\mathrm{W}_{\mathrm{L}, \mathrm{t}}=\frac{\sum\left(\mathrm{P}_{\mathrm{n}} \cdot \mathrm{F}_{\mathrm{C}}\right) \cdot \mathrm{F}_{\mathrm{O}} \cdot\left[\left(\mathrm{t}_{\mathrm{D}} \cdot \mathrm{F}_{\mathrm{D}}\right)+\mathrm{t}_{\mathrm{N}}\right]}{1000} & {\left[\frac{\mathrm{kWh}}{\mathrm{t}_{\mathrm{s}}}\right]} \\
\mathrm{W}_{\mathrm{P}, \mathrm{t}}=\frac{\sum \mathrm{P}_{\mathrm{pc}} \cdot \mathrm{t}_{\mathrm{s}}+\left(\mathrm{P}_{\mathrm{em}} \cdot \mathrm{t}_{\mathrm{e}}\right)}{1000} & {\left[\frac{\mathrm{kWh}}{\mathrm{t}_{\mathrm{s}}}\right]}
\end{array}
$$

where: $\mathrm{W}=$ annual energy required for lighting $[\mathrm{kWh}]$; $\mathrm{W}_{\mathrm{L}, \mathrm{t}}=$ energy for illumination $[\mathrm{kWh}] ; \mathrm{W}_{\mathrm{P}, \mathrm{t}}=$ energy for standby $[\mathrm{kWh}] ; \mathrm{A}=$ useful area of the building $\left[\mathrm{m}^{2}\right] ; \mathrm{P}_{\mathrm{n}}=$ total power for luminaires [W]; $\mathrm{P}_{\mathrm{pc}}=$ power for controls' standby $[\mathrm{W}] ; \mathrm{P}_{\mathrm{em}}=$ power for emergency battery recharge $[\mathrm{W}] ; \mathrm{F}_{\mathrm{C}}=$ constant illuminance factor $[-] ; \mathrm{F}_{\mathrm{D}}=$ daylight dependency factor $[-] ; F_{O}=$ occupancy dependency factor 
$[-] ; \mathrm{t}_{\mathrm{D}}=$ daylight time $[\mathrm{h}] ; \mathrm{t}_{\mathrm{N}}=$ daylight absence time $[\mathrm{h}]$; $\mathrm{t}_{\mathrm{e}}=$ battery charge time $[\mathrm{h}] ; \mathrm{t}_{\mathrm{s}}$ is the time step to which the calculation of $\mathrm{W}_{\mathrm{L}, \mathrm{t}}$ and $\mathrm{W}_{\mathrm{P}, \mathrm{t}}$ are referred (typically a year).

Daylight is taken into account through $\mathrm{F}_{\mathrm{D}}$. the standard approach introduces a segmentation of each building space, which is subdivided into an area that benefits from daylight ('daylit area' $A_{D}$, for which $F_{D}<1$ ) and an area that does not ('non-daylit area' $A_{N D}$, for which $F_{D}$ is assumed equal to 1 and no further calculation is needed).

$\underline{F}_{\underline{D}}$ is calculated as a function of two other factors: $\mathrm{F}_{\mathrm{D}, \mathrm{S}}$, or daylight supply factor, and $\mathrm{F}_{\mathrm{D}, \mathrm{C}}$, or lighting control factor. The first one is the factor that estimates the "daylight autonomy" of the zone under consideration, the second one accounts for the effectiveness of the type of lighting control system in exploiting daylight. For the calculation of $\mathrm{F}_{\mathrm{D}, \mathrm{S}}$ two different façade states are considered: with activated and not-activated solar and/or glare protections. The factor is then determined as a function of: site (latitude); climate, through the 'luminous exposure' LE; façade orientation; daylight amount without shading (Daylight Factor - D); target illuminance $\mathrm{E}_{\mathrm{m}}$; type of shading. As for the lighting control factor $F_{D, C}$, this is determined as a function of $\mathrm{D}$, type of lighting control system and of the illuminance required for the zone.

The occupancy dependency factor $\left(\underline{F}_{O}\right)$ is determined considering the relative time when a space is unoccupied (absence factor $\mathrm{F}_{\mathrm{A}}$ ) and the type of control system. The constant illuminance factor $\left(\underline{F}_{C}\right)$ accounts for the reduction of energy consumption that can be achieved with control systems designed to maintain the target illuminance during the overall lighting plant life.

Different types of lighting controls are considered in the calculation method: eight types of photodimming controls (manual, stepped, dimmed) and four types of occupancy controls (manual, switch off, switch on/off, dimmed). More information about the new calculation method of the EN15193 standard can be found in Aghemo et al. (2016), and Pellegrino et al. (2018).

\section{DIVA simulations}

DIVA for Rhino is a plug-in specifically conceived for the 3D modeller Rhino. It allows dynamic simulations of daylighting to be carried out using the validated algorithm Radiance for the calculation of photometric quantities. The photometric quantities are calculated through a combined approach, which relies on the daylight coefficient method and on the Perez 'all-sky weather' model. Using this combined approach, DIVA calculates the illuminance values over a grid of points, during the course of a year, with a time-step of one hour. Input data for the simulations, beside the climate file of the site, are the 3D model of the considered room/building, where a Radiance-compatible material needs to be assigned to each surface of the model. It is also possible to model static and moveable shades, through a detailed modeling of the geometry as well as of the materials. For moveable shades, designers can use a 'conceptual' blind (which has a diffuse light transmittance of $25 \%$ and is automatically pulled down whenever any point of the grid receives over $50 \mathrm{~W} / \mathrm{m}^{2}$ ). Alternatively, they can model different shading configurations and adopt different profile of usage. Further input data are: grid of sensors, target workplane illuminance and occupancy profile of the considered room. As far as the calculation of the energy demand for lighting is concerned, it is possible to specify the total power for luminaires installed in the room, also specifying the ballast loss factor and the standby power. Besides, different lighting and occupancy controls are available.

The output of the daylight simulation are: the Daylight Factor (D) and daylight climate-based metrics (CBDM), namely: Daylight Autonomy DA; continuous Daylight Autonomy $\mathrm{DA}_{\text {con }}$; spatial Daylight Autonomy sDA; Useful Daylight Illuminance UDI, Annual Sunlight Exposure ASE; Daylight Glare Probability DGP. The output of the energy calculation is the annual lighting energy demand in (kWh/year). This energy use, referred to the floor area, corresponds to the LENI index.

\section{Methods}

A set of case studies was defined for the analysis of the daylighting supplied in a room and the corresponding energy demand for lighting, calculated through both the analytical method and dynamic simulation. A reference room was chosen, whose plan sizes are $6 \mathrm{~m} \times 6 \mathrm{~m}$, with a floor-to-ceiling distance of $3 \mathrm{~m}$. The room has a single vertical opening (with a lintel height of $2.70 \mathrm{~m}$ and a sill height of $1 \mathrm{~m}$ above the floor), equipped with a glazing with a visible transmittance of 0.70 . The room was meant to be used as a cellular office, with a target illuminance of $500 \mathrm{~lx}$ and with an occupancy profile 8:00 through 17:00 (chosen in accordance with the Standard EN 15193$1: 2017$ to determine the daylight supply factor $F_{D, S}$ ).

A series of variables were parametrically modified to obtain a meaningful number of cases for which to compare the daylight contribution and the energy consumption for lighting determined analytically and from simulations. The analyses were carried out in two steps, one focused on the daylight supply in the room, one on the energy demand for lighting.

\section{Step 1: comparison of the daylight supply}

The following parameters were modified: site, opening size, type of shading, presence of a building ahead (obstruction angle of $45^{\circ}$ ), and orientation (see Table 1). As a result, a database of 176 cases was built.

For each case, $\mathrm{D}^{*}$ and $\mathrm{F}^{*} \mathrm{D}, \mathrm{S}$ were calculated analytically following the standard approach, while DIVA-for-Rhino simulations were run to calculate both the mean Daylight Factor $\left(\mathrm{DF}_{\mathrm{m}}\right)$ and the mean continuous Daylight

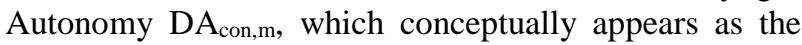
most consistent metric to be compared to $\mathrm{F}_{\mathrm{D}, \mathrm{s}}$, based on its definition in the EN 15193-2 (2017). Consequently, the comparison analytical method versus simulations was subdivided into two sub-steps:

- Step 1a: daylight factor ( $\mathrm{D}^{*}$ vs. $\left.\mathrm{DF}_{\mathrm{m}}\right)$

- Step 1b: daylight supply ( ${ }^{*}{ }_{D, S}$ vs. $\left.\mathrm{DA}_{\text {con,m }}\right)$, according to what specified by de Boer et al. (2011).

The calculation of $\mathrm{D}^{*}$ and $\mathrm{F}_{\mathrm{D}, \mathrm{S}}^{*}$ according to the standard was done through an area-weighted average of $D$ and $F_{D, S}$ values determined for $A_{D}$ and $A_{N D}$. In more detail: 
- for the daylight factor: the $D$ value found for $A_{D}$ was averaged with a $D=0$ that was assumed for $A_{N D}$

- for the daylight supply factor: the $F_{D, S}$ value found for $A_{D}$ was averaged with a $F_{D, S}=0$ assumed for $A_{N D}$.

The difference between non-averaged $D-F_{D, S}$ and averaged $\mathrm{D}^{*}-\mathrm{F}_{\mathrm{D}, \mathrm{S}}{ }^{*}$ increases as the window area (and hence $A_{D}$ ) decreases. Figure 1 shows the three different $A_{D}$ for the three window types L1, L6, WW. For WW, $A_{D}$ covers the full room area, so $\mathrm{D}^{*}=\mathrm{D}$ and $\mathrm{F}_{\mathrm{D}, \mathrm{S}}^{*}=\mathrm{F}_{\mathrm{D}, \mathrm{S}}$; for $\mathrm{L} 6$ $\mathrm{A}_{\mathrm{D}} / \mathrm{A}_{\mathrm{ND}}=0.79$, so $\mathrm{D}^{*}=0.79 \mathrm{D}$ and $\mathrm{F}^{*}{ }_{\mathrm{D}, \mathrm{S}}=0.79 \mathrm{~F}_{\mathrm{D}, \mathrm{S}}$; for $\mathrm{L} 1$ $\mathrm{A}_{\mathrm{D}} / \mathrm{A}_{\mathrm{ND}}=0.44$, so $\mathrm{D}^{*}=0.44 \mathrm{D}$ and $\mathrm{F}_{\mathrm{D}, \mathrm{S}}^{*}=0.44 \mathrm{~F}_{\mathrm{D}, \mathrm{S}}$.

Table 1: variables changed for the calculation of the daylight supply.

\begin{tabular}{|c|c|c|c|}
\hline site & $\begin{array}{l}\text { London, UK } \\
\mathrm{L}=52.3^{\circ} \mathrm{N} \\
\mathrm{LE}=0.37\end{array}$ & $\begin{array}{l}\text { Turin, IT } \\
\mathrm{L}=45.5^{\circ} \mathrm{N} \\
\mathrm{LE}=0.43\end{array}$ & $\begin{array}{l}\text { Palermo, IT } \\
\mathrm{L}=38.1^{\circ} \mathrm{N} \\
\mathrm{LE}=0.50\end{array}$ \\
\hline window & $\begin{array}{l}\mathrm{L} 1 \\
1 \mathrm{~m} \times 1.7 \mathrm{~m} \\
\text { WWR=0.09 } \\
\text { carcass area } \\
1.70 \mathrm{~m}^{2}\end{array}$ & $\begin{array}{l}\text { L6 } \\
6 \mathrm{~m} \times 1.7 \mathrm{~m} \\
\text { WWR }=0.57 \\
\text { carcass area } \\
10.2 \mathrm{~m}^{2}\end{array}$ & $\begin{array}{l}\text { WW } \\
6 \mathrm{~m} \times 3 \mathrm{~m} \\
\mathrm{WWR}=1 \\
\text { carcass area } \\
18 \mathrm{~m}^{2}\end{array}$ \\
\hline shading & \multicolumn{3}{|c|}{$\begin{array}{ll}\text { no shading for glare } & \text { blind for glare } \\
\text { protection } & \text { protection }\end{array}$} \\
\hline obstr. angle & \multicolumn{3}{|l|}{$0^{\circ}$} \\
\hline orientation & \multicolumn{3}{|l|}{ South S } \\
\hline
\end{tabular}

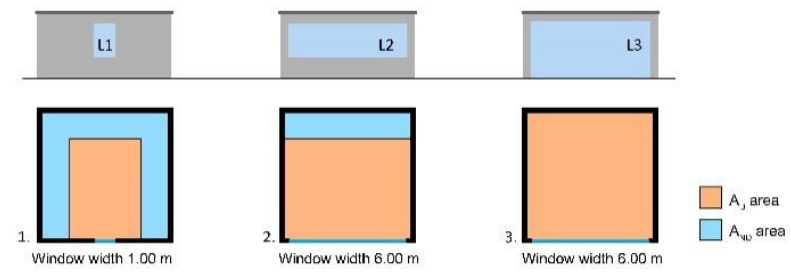

Figure 1: Definition of the area $A_{D}$ and $A_{N D}$ for the three window configurations $L 1, L 6, W W$.

The climate files from Energy Plus were used to run DIVA simulations as well as to calculated the luminous exposure $\mathrm{LE}=\mathrm{H}_{\mathrm{dir}} / \mathrm{H}_{\mathrm{glob}}$, which was then used as input for the analytical calculation of $\mathrm{F}^{*} \mathrm{D}, \mathrm{S}$. For simulations, a grid of sensors was positioned over the workplane $(0.8 \mathrm{~m}$ above the floor), with a spacing of $50 \mathrm{~cm}$.

Step 2: comparison of the energy demand for lighting

For the next stage of the study, a set of nine cases from the whole database was selected. These had close values of $\mathrm{F}_{\mathrm{D}, \mathrm{S}}^{*}$ and $\mathrm{DA}_{\text {con,m, }}$, able to cover the full range of daylight supply $\left(\mathrm{F}_{\mathrm{D}, \mathrm{S}}^{*}\right.$ in the range $\left.7 \% \div 85 \%\right)$. This was done to proceed with the analysis of the energy consumption starting from cases for which the daylight supply was of the same magnitude.

The following assumptions were made for the calculation of the energy demand for lighting: the room was assumed to be lit through 4 LED luminaires, each with a power of $54 \mathrm{~W}$, with a ballast loss factor of $20 \%$ and a stand-by power of $0.3 \mathrm{~W}$ (as a result, the total power installed in the room was $259.2 \mathrm{~W}$, with a standby power of $1.2 \mathrm{~W}$ ). For the different cases, the lighting power was kept constant, while the lighting control was varied, to investigate the consistencies and differences in the calculation of the energy demand based on the type of the lighting control system.

Two further analyses were carried out: one related to the impact of the estimated space's occupancy and one to the impact of the luminaires position in the space.

According to the method proposed in the EN 15193$1: 2107$, the luminaires position in the room implies the attribution of the power to $A_{D}$ and/or to $A_{N D}$. Following up this possibility, cases with window type L1 were used to analyse the effect of this option. For these cases, three assumptions were made: (i) all the four luminaires attributed to $A_{D}$; (ii) two luminaires attributed to $A_{D}$ and two to $A_{N D}$; (iii) all the four luminaires attributed to $A_{N D}$. Cases with window type L6 and WW were not included in this stage, as they offer a too limited area $\mathrm{A}_{\mathrm{ND}}$ compared to the area $A_{D}$. It is therefore unlikely to have luminaires in $A_{N D}$. For all these cases, all luminaires were attributed to $A_{D}$ only (Fig. 2). For each room configuration, six different lighting/occupancy controls were studied: (i) manual switch on-off; (ii) photodimming with standby power; (iii) photodimming without standby power; (iv) manual switch with occupancy on-off; (v) manual switch with occupancy off; (vi) photodimming+occupancy off.

\section{Results}

\section{Step 1a: comparison of the daylight factor calculated analytically and through simulations}

Figure 2 shows the daylight factor results (analytical and from simulations) for the entire database. Plotting the $\mathrm{D}^{*}$ values versus $D_{m}$ values (Fig. 3a) shows a robust correlation $\left(\mathrm{R}^{2}=0.98\right)$. In spite of this, a difference in the estimates is observed: the relative difference between $\mathrm{D}^{*}$ and $\mathrm{DF}_{\mathrm{m}}$ for all the cases analysed is in the range $0 \div$ $-47.4 \%$ (Fig. 3b), with greater differences for lower and intermediate daylight factor values. However, the analytical approach underestimates the results from simulations for all the cases analysed.

\section{Step 1b: comparison of the daylight supply calculated analytically and through simulations.}

Figure 3 shows the daylight contribution in the spaces analysed through the analytical method $\left(\mathrm{F}^{*} \mathrm{D}, \mathrm{S}\right)$ compared to the corresponding $\mathrm{DA}_{\mathrm{con}, \mathrm{m}}$ values from DIVA.

The correlation between analytical and simulation results shows a good correlation coefficient $\left(\mathrm{R}^{2}=0.87\right)$, but lower than the one observed for the daylight factor.

The following considerations can be drawn:

- range of differences: this is far broader $(+26.4 \% \div$ $-217.4 \%$ ) compared to what observed for the daylight factor. Except from some E-facing cases with shades, in almost all other cases $\mathrm{F}^{*}{ }_{\mathrm{D}, \mathrm{S}}$ provides a lower estimation of the daylight supply than $\mathrm{DA}_{\mathrm{con}, \mathrm{m}}$

effect of climate: the highest differences between analytical and simulation results were observed for Palermo, then for Turin and for London: the absolute average percent difference is $-71.4 \%,-43.7 \%$, and $-35.6 \%$, respectively (sign 'minus' for the absolute difference indicates that the $\mathrm{F}_{\mathrm{D}, \mathrm{S}}^{*}$ results are lower than the $\mathrm{DA}_{\mathrm{con}, \mathrm{m}}$ results from simulations) 


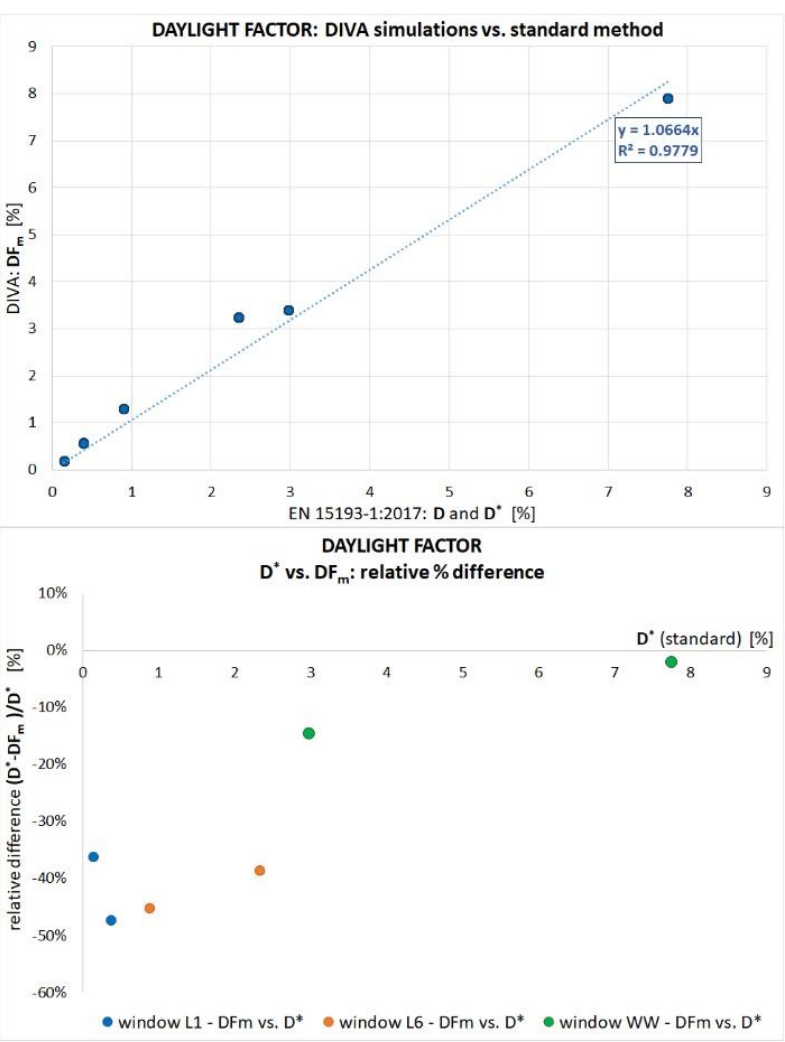

Figure 2: $D F_{m}$ from DIVA vs. analytical $D^{*}$.

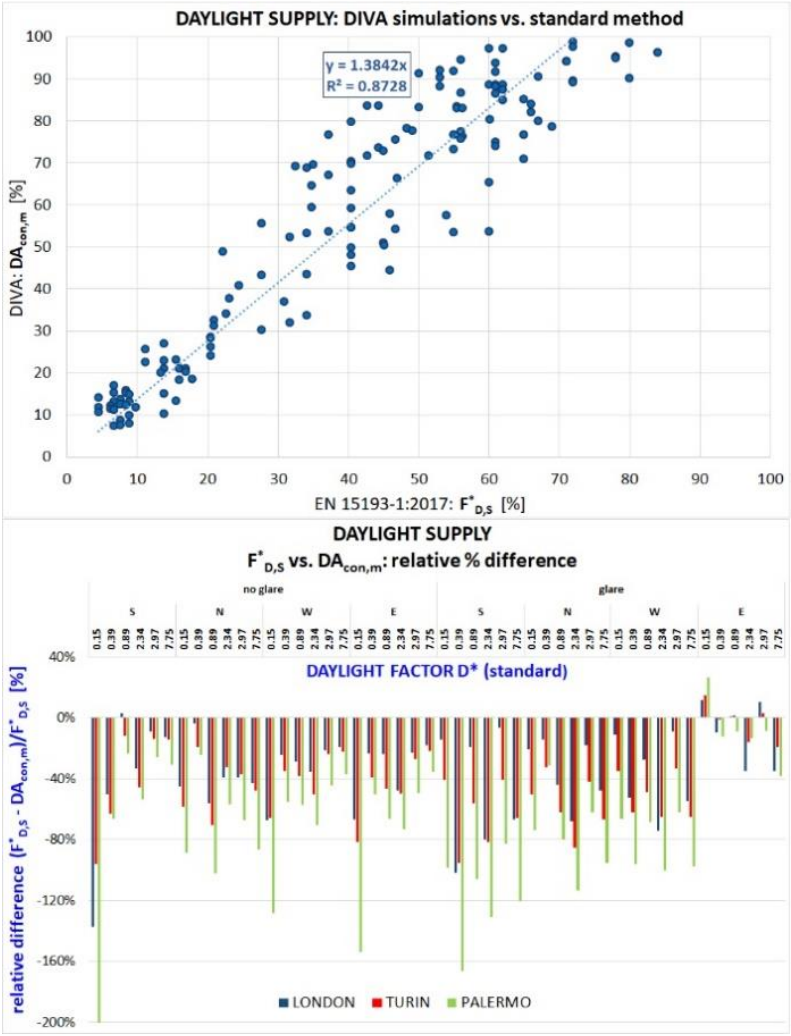

Figure 3: Daylight supply: $F_{D . S}^{*}$ vs. DA $A_{c o n, m}$.

- effect of obstruction: the relative difference values between the analytical and the simulations results for cases without and cases with obstruction were found to be similar (absolute average percent difference: $-47.9 \%$ and $-52.6 \%$, respectively) effect of orientation and of glare protection system: among the four orientations considered, three $(\mathrm{S}, \mathrm{N}$, W) showed differences between analytical and simulations results of a comparable magnitude (absolute average percent difference: $-53.5 \%$ for $\mathrm{N}$, $-63.5 \%$ for $\mathrm{S}$ and $-51.6 \%$ for $\mathrm{W})$. The magnitude is significantly different for E-facing cases: $-32.4 \%$. This peculiar trend is analysed in more detail in Figure 4, where results for S- and E-facing cases are plotted for both the analytical and the simulation approach. The results for S-facing cases show that the difference between the standard approach and simulation is greater for cases with than without the sun protection system, while the opposite applies for E-facing cases.

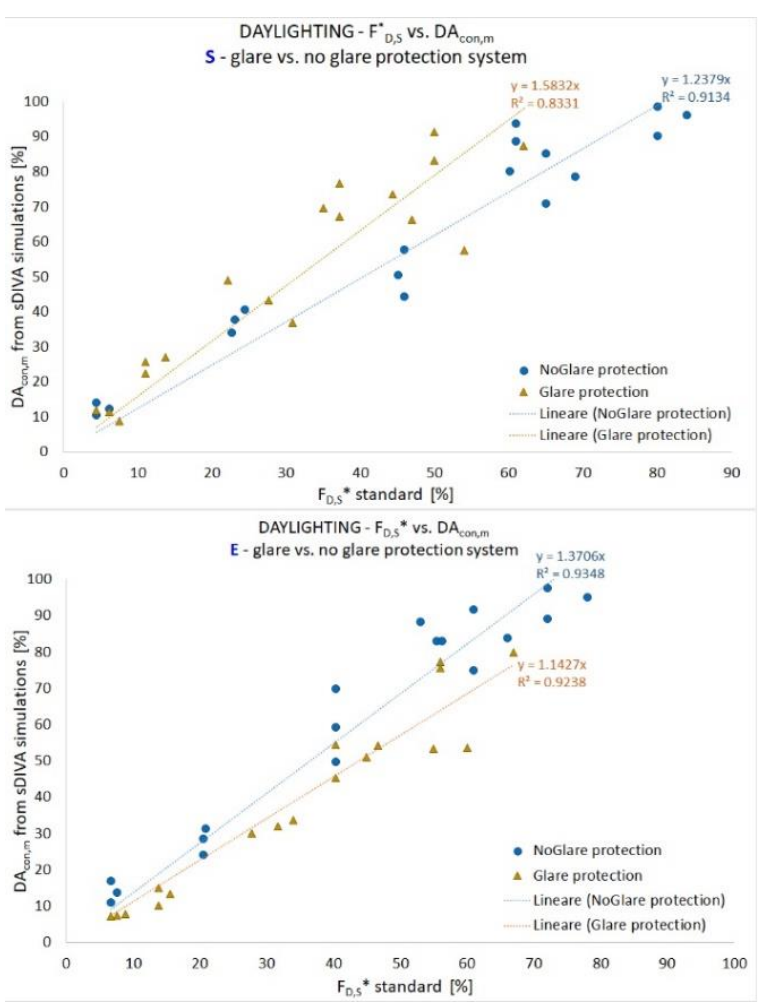

Figure 4: Effect of glare protection system (blinds) on results for South and East-facing cases.

Step 2: comparison of the energy demand for lighting calculated analytically and through simulations

As mentioned earlier, a limited set of nine cases were extracted from the entire database to proceed with the analysis of the energy demand for lighting (LENI values vs. $\mathrm{ED}_{\text {lighting }}$ from simulations). Cases with similar $\mathrm{F}_{\mathrm{D}, \mathrm{S}}$ and $\mathrm{DA}_{\text {con }}$ values were identified for this purpose, so as to have situations with a comparable estimated daylight amount. The nine cases were then grouped based on the daylight supply in three categories (Table 2): 3 cases with a 'low' $\mathrm{F}_{\mathrm{D}, \mathrm{S}}^{*}<30 \%$ (LOW); 3 cases with $\mathrm{F}_{\mathrm{D}, \mathrm{S}}^{*}$ in the range $30 \%-60 \%$ (MED); 3 cases with $F^{*}$, $>$ $>60 \%$ (HIGH).

These cases account for conditions from little to very high daylight availability, and represent all the variables assumed: location (London LON, Turin TUR, Palermo PAL), window size (L1, L6, WW), obstruction angle $\left(0^{\circ}\right.$, $45^{\circ}$ ), presence/absence of a shade (NoGlare, Glare). 
As explained earlier, two further analyses were carried out: (i) the impact on $E D_{\text {lighting }}$ due to a different attribution of the luminaire power to $A_{D}$ and/or to $A_{N D}$; (ii) the impact on $\mathrm{ED}_{\text {lighting }}$ of the absence factor $\mathrm{F}_{\mathrm{A}}$, which is included in the standard approach but not in DIVA. For all the nine cases selected, the LENI was calculated using two $F_{A}$ values: $F_{A}=0.3$ (value for cellular offices for 2 to 6 persons) and $F_{A}=0.9$ (value for bathrooms).

Table 2: cases selected for the analysis of the energy demand for lighting.

\begin{tabular}{|c|c|c|c|}
\hline$\#$ & case & $\begin{array}{l}\mathbf{F}_{\mathrm{D}, \mathrm{S}}^{*} \\
{[\%]}\end{array}$ & $\begin{array}{l}\mathbf{D A}_{\text {con,m }} \\
{[\%]}\end{array}$ \\
\hline LOW1 & PAL_L1_E_45﹎Glare & 6.7 & 7.3 \\
\hline LOW2 & LON_L1_W_45 _ _Glare & 8.9 & 9.9 \\
\hline LOW3 & LON_L1_N_0 ${ }^{\circ}$ NoGlare & 17.8 & 18.5 \\
\hline MED1 & PAL_L6_E_45음are & 27.7 & 30.2 \\
\hline MED2 & TUR_L6_S_45 _ _NoGlare & 45.1 & 50.4 \\
\hline MED3 & TUR_WW_E_45 ${ }^{\circ}$ Glare & 55.0 & 53.4 \\
\hline HIGH1 & LON_WW_W_45 _- $5^{\circ}$ Glare & 60.0 & 65.4 \\
\hline $\mathrm{HIGH} 2$ & LON_WW_S_45﹎NoGlare & 65.0 & 70.8 \\
\hline HIGH3 & TUR_WW_S_0 ${ }^{\circ}$ NoGlare & 85.0 & 96.2 \\
\hline
\end{tabular}

\section{Effect of control systems}

Fig. 5 shows the different values of the $E D_{\text {lighting, as }}$ calculated through the analytical method and simulations, for the nine cases selected, with the six control systems. Supplementary information is provided in Fig. 6, which shows the relative difference of the analytical LENI values with respect to the corresponding $\mathrm{ED}_{\text {lighting values }}$ from DIVA. Negative values show that DIVA simulation overestimate the analytical results and vice versa.

The following consideration can be drawn:

- manual control (Fig. 5a): the analytical results underestimate the DIVA results for cases LOW1-2-3 and MED2 (44.4\% of cases), while analytical results overestimating simulations for cases MED1-3 and HIGH1-2-3 (55.6\% of cases). Analysing the data for the different daylight supply, the differences are as follows: $-26.5 \%$ for LOW cases, $+15.0 \%$ for MED cases, $+68.0 \%$ for HIGH cases. The highest difference was found for case HIGH3 $(+128.7 \%)$

- photodimming control (Fig. 5b): analytical values generally underestimate simulations $(61.1 \%$ of cases $)$, with an average difference of $+55.8 \%$. Similarly to manual controls (but with a higher magnitude), the analytical method underestimate simulations for LOW cases and the opposite applies as the daylight supply increases (MED and HIGH cases). In detail, the differences are: $-37.9 \%$ for LOW cases, $+10.0 \%$ for MED cases, $+119.1 \%$ for HIGH cases. Higher differences were found for cases with standby rather than without (average difference: $+61.2 \%$ vs. $+50.3 \%$ ) occupancy control (Fig. 5c): overall, analytical results underestimate simulations $(83.3 \%$ of cases), with an average difference of $-40.7 \%$. Two different trends were observed: for switch+occupancy on-off controls, analytical values are constantly lower than simulations (average difference: $-50.4 \%$ ). Differently, for switch+occupancy off controls, analytical values generally underestimate simulations for LOW and MED cases (average differences: $-43.0 \%$ and $-34.6 \%$ ), and overestimate simulations for HIGH cases (average difference $=+44.6 \%$ )

photodimming+occupancy OFF control (Fig. 5d): analytical values mostly underestimate simulations (77.8\% of cases, i.e. all cases but HIGH1-3), with a relative difference of $-39.3 \%$. In detail, the differences are: $-44.5 \%$ for LOW cases, $-18.7 \%$ for MED cases, $+54.8 \%$ for HIGH cases.
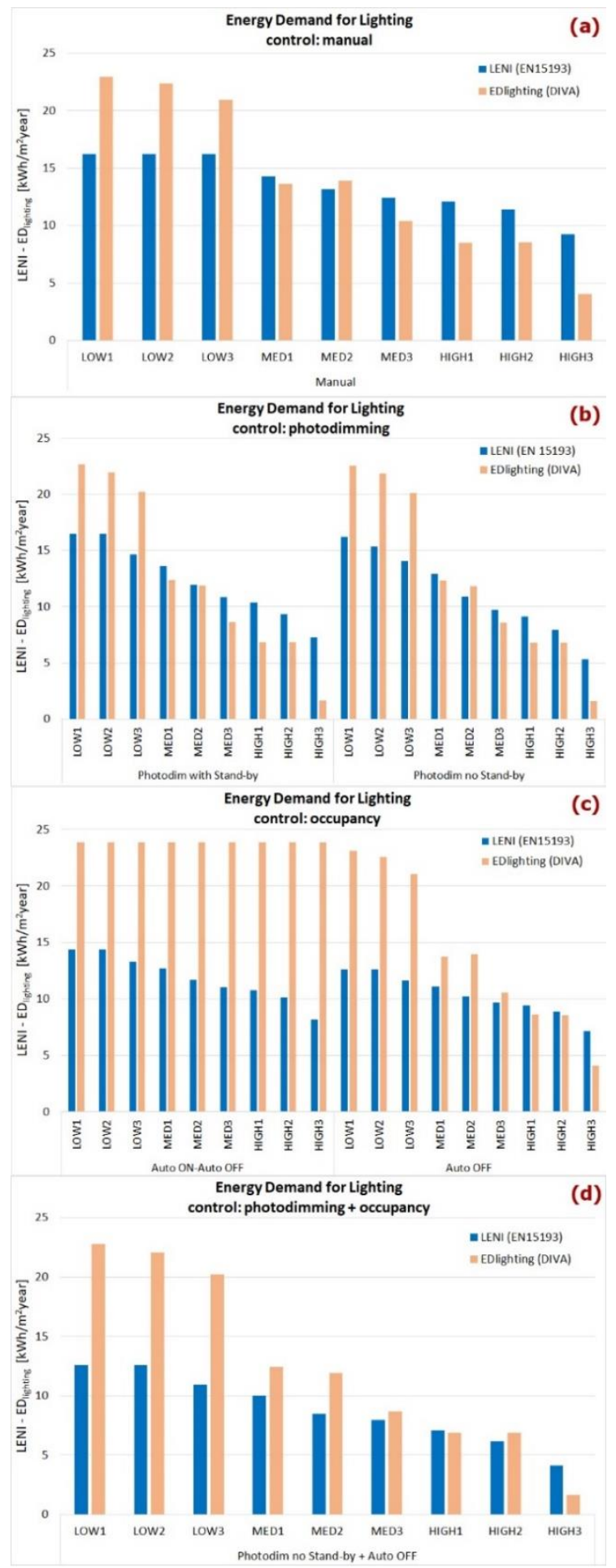

Figure 5: Energy demand for lighting for the 9 cases analyzed in step 2, for different control systems. 


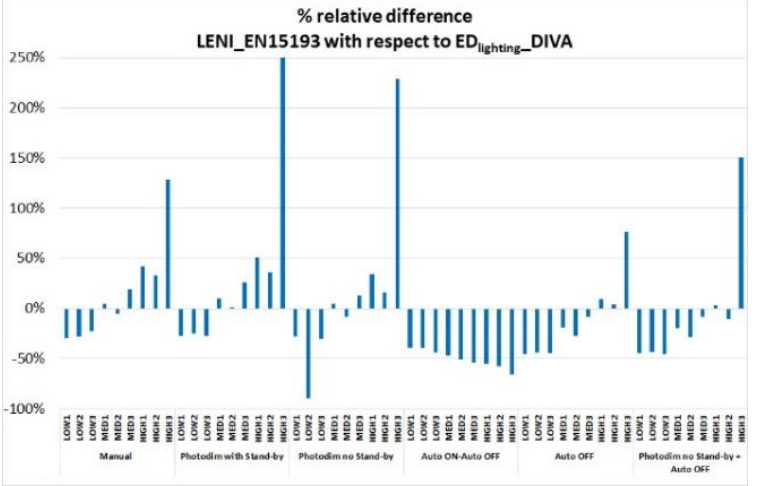

Figure 6: Relative difference of $E D_{\text {lighting, as calculated }}$ through the analytical and the simulation method.

\section{Effect of luminaire attribution to $A_{D}$ and/or $A_{N D}$}

Fig. 7 shows the impact on LENI values of a different attribution of the luminaire power to $A_{D}$ and/or to $A_{N D}$.

For the three controls (manual, photodimming without standby and photodimming without standby + auto off), the lowest LENI values were found when the luminaire power is attributed entirely to $A_{D}$. When luminaires are attributed half to $A_{D}$, half to $A_{N D}$, or entirely to $A_{N D}$, an increment in $\mathrm{ED}_{\text {lighting }}$ was observed: the average difference was $+23.2 \%$ and $+46.5 \%$, respectively.

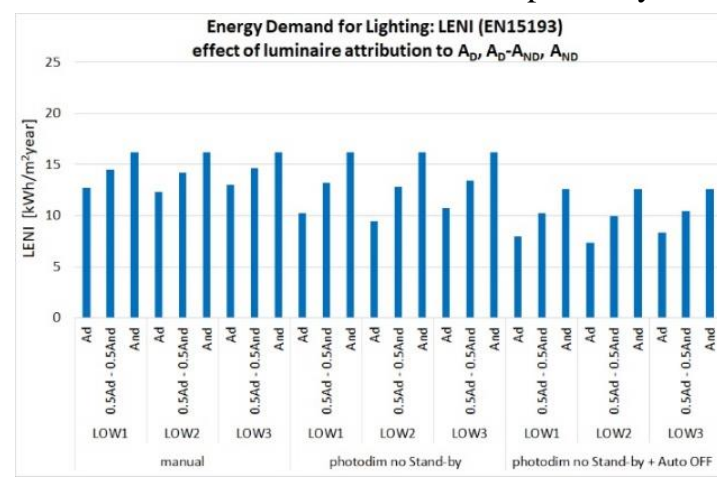

Figure 7: Impact on LENI values of a different attribution to the luminaire power to $A_{D}$ and/or $A_{N D}$.

\section{Effect of the absence factor $F_{A}$ (analytical method)}

Figure 8 focuses on the impact on $\mathrm{ED}_{\text {lighting }}$ of the absence factor $F_{A}$, which is part of the calculation of LENI. For this analysis, two sets of LENI values (one with $\mathrm{F}_{\mathrm{A}}=0.3$, one with $\mathrm{F}_{\mathrm{A}}=0.9$ ) were calculated for the nine cases and compared to the $\mathrm{ED}_{\text {lighting }}$ from DIVA (which does not include a concept corresponding to $\mathrm{F}_{\mathrm{A}}$ ).

As one could expect, cases with $\mathrm{F}_{\mathrm{A}}=0.9$ show LENI values lower than what observed for $\mathrm{F}_{\mathrm{A}}=0.3$. The average relative difference was $-75.9 \%$, with lower values for cases with a manual control $(-67.0 \%)$, intermediate for cases with occupancy OFF controls $(-75.0 \%)$, and higher for cases with occupancy ON/OFF controls (-85.7\%).

The following trends were observed:

- cases with $F_{A}=0.3$ : a prevailing underestimation of the analytical method with respect to simulations $(70.4 \%$ of cases) was observed, with an average relative difference of $-38.7 \%$. For the different controls, the following average relative differences were found: $+34.8 \%$ for the manual control $(44.4 \%$ of cases with analytical values overestimating simulations results), $-50.4 \%$ for the occupancy OFF control $(100 \%$ of cases), and $-30.9 \%$ for the occupancy ON-OFF control (66.7\% of cases)

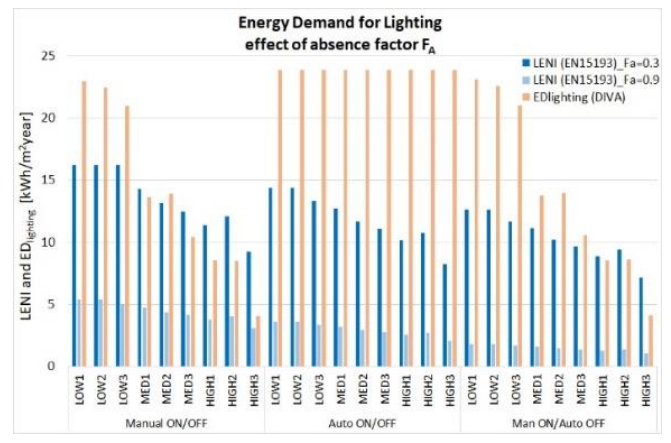

Figure 8: Impact on the $E D_{\text {lighting }}$ of a different $F_{A}$.

cases for $F_{A}=0.9$ : for all cases, the analytical method underestimates simulations, with the following average relative differences: $-78.8 \%$ (all cases), $-61.6 \%$ (manual), $-87.6 \%$ (occupancy OFF), $-87.3 \%$ (occupancy ON-OFF).

\section{Discussion}

The paper presented the results of a study that compared the output of two tools to calculate the daylight provision in a space and the corresponding $\mathrm{ED}_{\text {lighting: an analytical }}$ method, from the European standard EN 15193-1, and a dynamic simulation tool (DIVA-for-Rhino).

The comparison was carried out with regard to both the daylight supply in a room (step 1) and to the energy consumption for lighting (step 2), with the aim of quantifying the differences in the output provided by the two tools. Each tool accounts for all the influencing factors, through specific algorithms and with a different detail. The final estimate of the daylighting and of the energy use for lighting may change as a function of the tool adopted (Konstantoglou et al., 2016). The innovation of the study lies in the quantification of such differences.

As far as the daylight supply is concerned (step 1), the comparison was done in terms $\mathrm{D}^{*}$ (standard) vs. $\mathrm{DF}_{\mathrm{m}}$ (DIVA) and of $\mathrm{F}_{\mathrm{D}, \mathrm{s}}^{*}($ Standard $)$ vs. $\mathrm{DA}_{\text {con, } \mathrm{m}}(\mathrm{DIVA})$. The results of the study demonstrated that there is a very good correlation between analytical and simulation results about the $\mathrm{D}$ values $\left(\mathrm{R}^{2}=0.98\right.$, with differences in the range $0 \% \div-47.4 \%$, with average percent difference of $-30.4 \%$ ). Differences are higher for cases with lower daylight factor (window L1) and tend to decrease (down to $0 \%$ ) for higher daylight factor values (window $\mathrm{WW}$ ).

A lower correlation was observed $\left(\mathrm{R}^{2}=0.87\right)$ when comparing $\mathrm{F}_{\mathrm{D}, \mathrm{S}}^{*}$ to $\mathrm{DA}_{\mathrm{con}, \mathrm{m}}$, with an absolute average percent difference of $-50.2 \%$, with a maximum of $-217.4 \%$ of and a minimum of $1 \%$. Both analyses show that the analytical method underestimates the daylighting in a room with respect to DIVA simulations.

The lower correspondence of $\mathrm{F}^{*}{ }_{\mathrm{D}, \mathrm{S}}-\mathrm{DA}_{\mathrm{con}, \mathrm{m}}$ values with respect to $\mathrm{D}^{*}-\mathrm{DF}_{\mathrm{m}}$ is due to the greater complexity of the influencing factors, particularly to the way both climate, orientation and movable shades are considered in the two approaches. For the climate, the absolute average 
difference was higher for Palermo (71.4\%), intermediate for Torino (43.7\%) and lower for London (35.6\%).

The larger difference observed for Palermo seems to be linked to two peculiar features of the standard with regard to an unshaded spaces. First of all, to a space located at a latitude $30^{\circ}-45^{\circ}$ (i.e. Palermo), the standards attributes higher $\mathrm{F}_{\mathrm{D}, \mathrm{S}}$ compared to the same space at a latitude $45^{\circ}$ $60^{\circ}$ (i.e. London), as one would expect, but only for LE values up to 0.50 . Over this value, the opposite trend applies (Aghemo et al., 2016). This means that Palermo is granted by the standard a lower daylight supply than London. Furthermore, the EN15193-1 attributes $F_{D, S}<1$ also to spaces without blinds, thus assuming a certain use of the blinds also for conditions labelled as 'no glare protection system installed'.

For what concerns the orientation and the use of moveable shades, similar absolute difference were obtained for $\mathrm{N}$, $\mathrm{S}$, and $\mathrm{W}(-53.5 \%,-63.5 \%$ and $-51.6 \%)$, with analytical daylight supply underestimating simulations. A different magnitude was observed for E-facing cases (relative difference: $-32.4 \%$ ). The different trends seem to be due to the different algorithms used by the two approaches to model blinds, which is particularly evident when the same cases are compared for $\mathrm{W}$ or $\mathrm{E}$ orientation, with blinds. For these cases, the standard yields the same $\mathrm{F}_{\mathrm{D}, \mathrm{S}}^{*}$, while DIVA yields quite different $\mathrm{DA}_{\text {con,m }}$ values. The relative differences of $\mathrm{F}_{\mathrm{D}, \mathrm{S}}^{*} \mathrm{vs}$. $\mathrm{DA}_{\text {con,m }}$ ranged from $-128.3 \%$ to $9.0 \%$ for $\mathrm{W}$-facing cases, from $-153.8 \%$ to $+26.4 \%$ for $\mathrm{E}-$ facing cases. Furthermore, while the analytical method underestimates simulations for all E-facing cases, 20.4\% of $\mathrm{W}$-facing cases show an analytical value higher than the simulation result. This is due to the DIVA algorithm to model conceptual blinds: once glare is detected, the blind is pulled down and left in that position for the rest of day. This means that E-facing spaces remain shaded for longer periods compared to the same spaces facing $\mathrm{W}$.

A sensitivity analysis on the influencing factors implemented in the standard was presented in a previous paper from the same Authors (Aghemo et al., 2016).

As for the comparison of the energy demand for lighting (step 2), a general trend was observed quite independently of the different control analyzed: the analytical method tends to underestimate simulations for cases with LOW daylight supply, while the opposite applies for cases with HIGH daylight supply. The MED cases present different trends depending on the control system: for manual and photodimming controls, LENI values are higher than

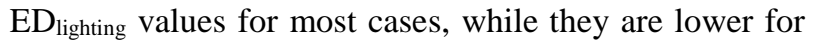
occupancy auto off controls (both stand-alone and with photodimming). With occupancy on-off controls, analytical values are constantly lower than simulations.

The above mentioned differences can also be explained (beside the different algorithms of the two methods) by the different number of hours used by the two tools when the same occupancy profile (from 8 am 'till $5 \mathrm{pm}$ ) is selected. According to the standard analytical approach, this profile results in a 2500 hours throughout a year (with $\mathrm{T}_{\mathrm{D}}=2500 \mathrm{~h}, \mathrm{~T}_{\mathrm{N}}=250 \mathrm{~h}$ ), while in DIVA an occupancy profile of $3285 \mathrm{~h}$ is generated. Consequently, for occupancy controls the longer occupancy profile in DIVA yields higher $\mathrm{ED}_{\text {lighting }}$ values. Differently, for dimming controls, LENI values overestimate simulations, although the reduced number of hours.

As for the impact on LENI values played by how luminaires are attributed to $A_{D}$ and/or $A_{N D}$, for both manual, photodimming and photodimming+auto off control an increment was observed when the luminaire power is attributed half to $A_{D}$, half to $A_{N D}$, or entirely to $\mathrm{A}_{\mathrm{ND}}$ (with respect to all luminaires in $\mathrm{A}_{\mathrm{D}}$ ): the average difference was $+23.2 \%$ and $+46.5 \%$, respectively.

As for the impact on LENI of the absence factor $F_{A}$, this leads to a different magnitude of the underestimation of analytical LENI values compared to DIVA simulations. Compared to DIVA values, an average relative difference was $-38.7 \%$ when a value $F_{A}=0.3$ was used; the difference decreased to $-78.8 \%$ when a value $\mathrm{F}_{\mathrm{A}}=0.9$ was used. It should be noted that the absence factor is a peculiar factor of the standard EN 15193-1 to account for non-continuous occupancy of a space, while the DIVA algorithms do not offer this option by default.

It should be noted that the results obtained are valid for the specific database of cases used for the analyses. This particularly applies to step (2), for which only cases that showed a comparable daylight supply $\left(\mathrm{F}^{*} \mathrm{D}, \mathrm{S}\right.$ vs. $\left.\mathrm{DA}_{\mathrm{con}, \mathrm{m}}\right)$ were used. This was made with the aim of quantifying the impact of a number of different manual, dimming and occupancy controls on the $\mathrm{ED}_{\text {lighting. A more general }}$ assessment of the energy demand for lighting should be done for all the cases of the database, also the ones with discrepancies in the calculation of the daylight supply.

As a last comment, it is worth noticing that all analyses are based on weighing both the daylight factor $\mathrm{D}$ and the daylight supply factor $\mathrm{F}_{\mathrm{D}, \mathrm{S}}$ (standard approach) as a function of the ratio $A_{D} / A_{N D}$ (thus calculating $D^{*}$ and $\mathrm{F}_{\mathrm{D}, \mathrm{S}}^{*}$ ). The results would change significantly using $\mathrm{D}$ and $\mathrm{F}_{\mathrm{D}, \mathrm{S}}$, without weighing: this would mean that a designer would apply $\mathrm{D}$ an $\mathrm{F}_{\mathrm{D}, \mathrm{S}}$ value to the entire room area instead of the daylit area $A_{D}$ only. Figures 9 and 10 show how the differences between simulations and the analytical method change when $\mathrm{D}-\mathrm{F}_{\mathrm{D}, \mathrm{S}}$ rather than $\mathrm{D}^{*}$ $\mathrm{F}_{\mathrm{D}, \mathrm{S}}^{*}$ are used. Clearly, $\mathrm{D}^{*}$ and $\mathrm{F}_{\mathrm{D}, \mathrm{S}}^{*}$ are lower compared to $\mathrm{D}$ and $\mathrm{F}_{\mathrm{D}, \mathrm{S}}$, especially for cases with $\mathrm{L} 1$ (which have have the smallest $\left.A_{D}\right)$ and, to a minor extent, with L6 ( $A_{D}$ almost half of the room), while for cases with $\mathrm{WW}$, no difference occurs as $A_{D}$ coincides with the room area. The following main considerations can be drawn:

daylight factor: using $\mathrm{D}$ and $\mathrm{F}_{\mathrm{D}, \mathrm{S}}$ results in a decrease of the difference between the analytical and the simulations results. The regression line shows an even better correlation $\left(\mathrm{R}^{2}=0.99\right.$, compared to $\mathrm{R}^{2}=0.98$ when $\mathrm{D}^{*}-\mathrm{F}^{*} \mathrm{D}, \mathrm{S}$ are used). On the other hand, for windows L1, analytical results are higher than the simulations values, unlike what happens using D-F $\mathrm{F}_{\mathrm{D}, \mathrm{S}}$ daylight supply: the correlation is less robust $\left(\mathrm{R}^{2}=0.76\right.$, compared to $\mathrm{R}^{2}=0.87$ for $\left.\mathrm{D}^{*}-\mathrm{F}^{*} \mathrm{D}, \mathrm{S}\right)$ and the analytical results overestimate the simulations values for a much higher number of cases compared to what observed when $\mathrm{D}^{*}-\mathrm{F}^{*} \mathrm{D}, \mathrm{S}$ are used $(38.2 \%$ vs. $5.6 \%)$. 
Building practitioner have therefore two types of analysis tools (analytical vs. dynamic simulation) to calculate the daylight supply and the $\mathrm{ED}_{\text {lighting }}$ for a room. Similarities and discrepancy were discussed in the study. The standard has the merit to supply an analytical method that is relatively user friendly; despite some simplifications, it accounts for climate, orientations, moveable shades, occupancy and dimming controls etc. The method is for the earliest design phases, when advanced simulation is still premature as a detailed model is not available yet. Advance simulations allow analyses to be carried out with a high level of detail, by implementing, in principle, any value of climate, physical and optical properties and yielding results on a scientific basis. Nonetheless, the simulation results also depend on the specific algorithm of the software that is used (Ghobad, 2018).

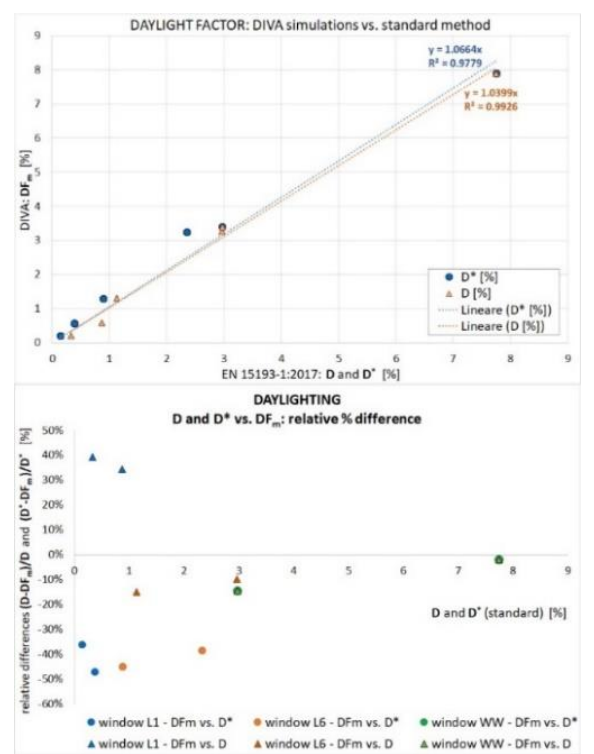

Figure 9: Analytical vs. simulated daylight factor: impact of using $D$ rather $D^{*}$.

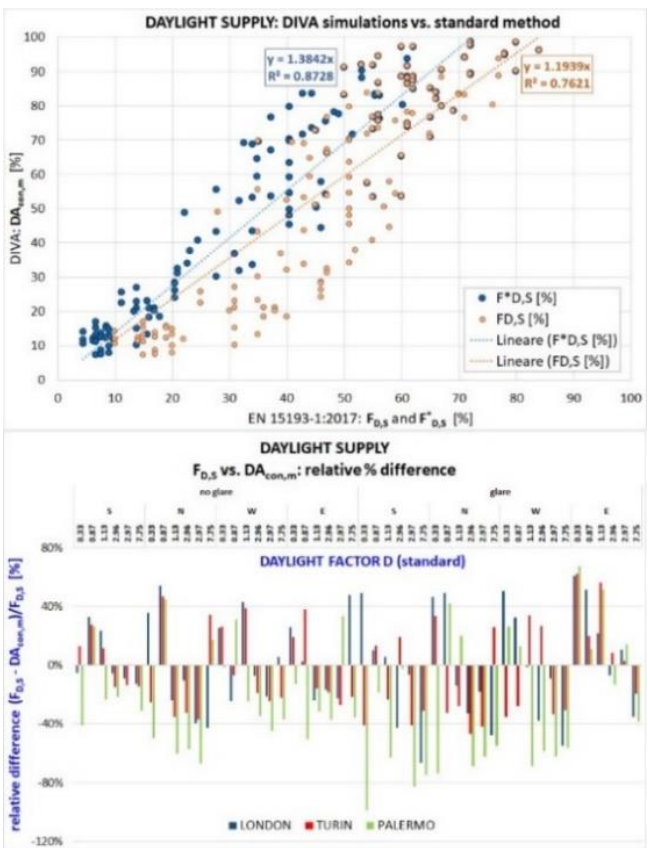

Figure 10: Analytical vs. simulated daylight supply: impact of using $F_{D, S}$ rather $F_{D, S}^{*}$.

\section{Conclusions}

The evaluation of daylighting contribution and of the energy performance for lighting in a building is a key aspect in the current design practice. The availability of simplified calculation methods allows these aspects to be considered since the earliest design phases. On the other hand, designers have advanced simulation tools. In this context, this study compared the analytical method of the standard EN15193-1:2017 to calculate the LENI index to DIVA-for-Rhino, a dynamic simulation tool.

The results showed a good correlation between the parameters to estimate the daylight supply. However, the differences, especially for what concerns the comparison $\mathrm{F}_{\mathrm{D}, \mathrm{S}}^{*}$ vs. $\mathrm{DA}_{\text {con,m, }}$, are sometimes relevant, particularly for climate conditions that deviate from the data reported in the standard. Similarly, differences in the range $-65 \%$ $+347 \%$ were observed in the calculation of $E_{\text {lighting }}$.

\section{Acknowledgements}

The study was conducted in the frame of a research contract committed by ENEA (Italian Energy Agency). The Authors thank Simonetta Fumagalli and Laura Blaso.

\section{References}

Aghemo, C., Blaso, L., Fumagalli, S., Lo Verso, V.R.M., \& Pellegrino, A. (2016). The new prEN 15193-1 to calculate the energy requirements for lighting in buildings: comparison to the previous standard and sensitivity analysis on new influencing factors. Energy Procedia 101, 232-239.

Comité Européen de Normalisation CEN (2017). Energy performance of buildings - Energy requirements for lighting - Part 1: Specifications (EN 15193-1:2017).

de Boer, J, \& Margenthaler, K. (2011). A simple general method to rate daylight supply of indoor spaces with vertical façades. IBP Report WB154/2011e.

Dubois, M.-C., \& Blomsterberg, A. (2011). Energy saving potential and strategies for electric lighting in future North European, low energy office buildings: A literature review. Energy and Build. 43, 2572-2582.

Ghobad, L. (2018). Daylighting and energy simulation workflow in performance based building simulation tools. 2018 Building Performance Analysis Conference. Chicago (IL,USA), 26-28 September 2018.

International Organisation for Standardisation ISO (2014). Calculation of the impact of daylight utilization on the net and final energy demand for lighting (ISO 10916:2014).

Konstantoglou, M., \& Tsangrassoulis, A. (2016). Dynamic operation of daylighting and shading systems: A literature review. Renew. and Sust. Energy Reviews 60, 268-283.

Pellegrino, A., Lo Verso, V.R.M., \& Paragamyan, A. (2018). Validation of the EN 15193:2017 calculation method to estimate the daylight supply in a building: comparison with dynamic climate-based simulations. Proc. of IBPC 2018: Syracyse (NY, USA), 23-26 September 2018. 